\title{
O uso de podcasts no desenvolvimento da oralidade em língua inglesa
}

\author{
Adrina Silva \\ UNIGRANRIO \\ Luciana Valeiras Duque \\ UNIGRANRIO \\ Solimar Patriota Silva \\ UNIGRANRIO
}

\begin{abstract}
Resumo
Sabemos que o desenvolvimento da competência oral dos aprendizes de língua inglesa em nossas escolas ainda está aquém do desejável para o domínio dessa língua estrangeira, devido a fatores diversos que vão desde a infraestrutura das escolas, com turmas lotadas, carência de materiais diversificados e pouco tempo de aula até a própria formação do professor. Neste artigo, objetivamos apresentar como o uso do recurso podcast pode ser útil para auxiliar o professor na tarefa de trabalhar a oralidade nas aulas de língua inglesa, especificamente para alunos do sexto ano do ensino fundamental, fase em que a maior parte das escolas oferta uma língua estrangeira no currículo. Espera-se com isso contribuir para a discussão acerca da necessidade e possibilidade de se desenvolver a habilidade oral do aluno nessa língua estrangeira.
\end{abstract}

Palavras-chave: língua inglesa - competência oral - podcasts

\begin{abstract}
We know that learners in our schools have not developed oral proficiency in English at a level that is desirable for the mastery of this foreign language. This is due to many factors, ranging from the infrastructure of schools, with crowded classrooms, lack of teaching materials and of sufficient class time, to teacher training. In this article, we introduce ideas on how podcasts can be a useful aid for the teacher in the task of teaching speaking skills in English as a foreign language, specifically to sixth grade students. These learners are at the stage in which most schools include a foreign language in their curriculum. The paper is expected to contribute to a discussion on the necessity and possibility of developing students' oral skills in this foreign language.
\end{abstract}

Keywords: English - oral competence - podcasts

\section{INTRODUÇÃO}

A motivação para este trabalho surgiu de nossa inquietação quanto às competências que devem ser desenvolvidas para o domínio de uma língua estrangeira. Essa indagação foi tomando forma, seja através de leitura de literatura da área, da observação de aulas de 
professores regentes e da discussão desses aspectos nas aulas da disciplina de Estágio Supervisionado de Língua Inglesa na formação inicial dos futuros professores de língua inglesa.

Percebemos que a oralidade ainda é uma das habilidades menos trabalhadas em nossas escolas, especialmente nas escolas públicas. Vários fatores contribuem para essa constatação. O pouco tempo que é destinado a essa disciplina, com duas horas/aula semanais, em turmas com trinta a quarenta alunos, a falta de material diversificado para que o aluno seja exposto ao idioma em sua modalidade oral e as próprias lacunas na formação docente, visto que muitos professores, embora consigam ler e escrever, também não dominam a habilidade de falar na língua estrangeira.

Desta forma, este artigo tem por finalidade apresentar a relevância do desenvolvimento oral nas aulas de língua estrangeira, especificamente nas aulas de língua inglesa, objeto de estudo deste trabalho. Cremos que a exposição a situações que levem o aluno a falar a língua estudada deve ser feita logo nos primeiros anos de contato com a língua para que ele perceba seu progresso e fique ainda mais motivado para a aprendizagem. Acreditamos que os alunos que percebem poder falar a língua estrangeira estudada em contextos reais de uso, ainda que em nível básico, sentem-se mais dispostos a continuar aprendendo. Por fim, apresentamos como as novas tecnologias inseridas no ensino de língua estrangeira podem ser úteis no ensino e, em especial, como os podcasts podem ser preciosa ferramenta nesse trabalho sistemático de desenvolver a habilidade oral de nossos alunos.

Esperamos contribuir com algumas reflexões acerca da necessidade de o ensinoaprendizagem de língua inglesa como língua estrangeira dar conta do desenvolvimento da competência oral dos alunos e apresentar possibilidades para que esse trabalho se efetive em nossas salas de aula, a despeito de todas as mazelas do sistema escolar atual.

\section{O ENSINO-APRENDIZAGEM DA LÍNGUA INGLESA COMO LINGUA ESTRANGEIRA}

Nos últimos anos o sistema educacional brasileiro vem passando por transformações, objetivando melhoria na qualidade do ensino e, por isso, o currículo educacional passou por uma série de adaptações. Primeiro, em 1961, foi publicada a primeira Lei de Diretrizes e Bases (LDB), a qual retirava a obrigatoriedade do ensino da língua estrangeira das escolas. Dez anos depois, a LDB de 1971 reduziu o tempo de 
escolaridade, tendo foco no ensino profissionalizante e provocando redução da carga horária de Língua Estrangeira (LE). Entretanto, com a LDB vigente tornou-se obrigatório o ensino da LE a partir do sexto ano.

Em 1998, os Parâmetros Curriculares Nacionais de Língua Estrangeira (PCN) apresentaram os objetivos da disciplina, sugerindo uma abordagem socio-interacional para o ensino da LE. Os PCN de LE do Ensino Médio mostram que

no âmbito da LDB, as Línguas Estrangeiras Modernas recuperam, de alguma forma, a importância que durante muito tempo lhes foi negada, já que elas assumem a condição de ser parte indissolúvel do conjunto de conhecimentos essenciais que permitem ao estudante aproximar-se de várias culturas e, consequentemente, propiciam sua integração num mundo globalizado. (PCN, 2000, p. 25)

Exigências não só do mercado de trabalho, em razão do impacto da tecnologia da informática na sociedade, mas do mundo em geral, fazem a escola responder à necessidade de aprendizagem de, pelo menos, uma Língua Estrangeira (LE). Especificamente no caso da língua inglesa, vemos que seu conhecimento e domínio podem facilitar o acesso às redes de informação e do próprio mercado de trabalho.

Leffa (1999, p. 10) diz que o estudo da língua é importante no sentido de uma participação ativa na sociedade, pois a LE passa a ter um papel cada vez maior. O ensino da língua não deve ter só objetivos instrumentais como falar, ler e escrever; ele deve ser orientado para objetivos educacionais mais amplos, contribuindo para a formação plena do cidadão. Isso envolve o desenvolvimento da capacidade de reflexão e o conhecimento cultural de civilizações estrangeiras, diferentes tradições e ideais de outros povos.

Considerando aspectos de uma realidade transformada pela globalização, o aprendizado de uma segunda língua pode levar os alunos a ampliar conhecimento de mundo. A Língua Inglesa está ligada à realidade do mercado de trabalho, do mundo acadêmico e até mesmo da vida pessoal. Os próprios PCN de LE $(1998$, p.20) afirmam que uma justificativa social para inclusão de uma Língua Estrangeira no currículo é determinada pela função desta na sociedade e a língua escolhida para ser estudada é de acordo com a exigência, cultura e história da região.

Ainda segundo os PCN de LE (1998, p.65), no ensino fundamental, os objetivos de estudar a língua decorrem do papel formativo no currículo, porém mais especialmente em promover o acesso à tecnologia da comunicação e à interação com o mundo no qual 
circulam os estudantes, mundo este permeado por músicas, filmes e comerciais com a predominância do inglês.

Pode-se mencionar a importância do estudo da língua inglesa no campo profissional, o qual proporciona potencial de empregabilidade mais alto; academicamente, desenvolve o pensamento crítico e, no campo pessoal, promove conhecimento de outras culturas. Além disso, os alunos convivem com uma série de palavras em inglês no seu cotidiano devido à influência que ela exerce em nossa cultura, como por exemplo jeans, shopping, milkshake, pet shop, lan house, diet, show, entre tantas outras. Por fim, acreditamos que o domínio de uma língua estrangeira nos insere em uma nova cultura, em um mundo novo e nos permite o direito de exercer a cidadania no mundo.

\section{O processo de ensino-aprendizagem de uma língua estrangeira}

Ao planejarmos uma boa aula, precisamos analisar muitos aspectos para que o processo de ensino-aprendizagem de uma língua estrangeira seja bem sucedido. Faz-se necessário que o professor conheça bem os métodos de ensino, ainda mais hoje em dia, quando não há mais apenas um método que deve ser escolhido em detrimento de outro. Por isso mesmo, esse ecletismo metodológico requer que o professor tenha uma formação mais ampla, crítica e autônoma para fazer suas escolhas e práticas de modo intencional e consistente (VILAÇA, 2008, p.83).

O professor pode extrair o que for necessário de cada um desses métodos para perceber o que devemos ou não levar para a sala de aula, pois, segundo Marques (2011, p.24), podemos criar nossa própria abordagem de ensino de idiomas, e esta pode ser eclética e esclarecida. Eclética porque podemos escolher de cada um dos métodos e das abordagens existentes o que for necessário para o ensino de uma língua estrangeira e esclarecida porque nossos conhecimentos teóricos estarão baseados em seus princípios fundamentais ao selecionarmos as técnicas que utilizaremos em sala.

Durante muito tempo, a busca por um método perfeito fez com que cada método novo que surgisse rompesse com o anterior. Conforme afirma Prator (1979, p.05, apud VILAÇA 2008, p.74), “os defensores e adeptos de um método novo negavam a validade dos métodos anteriores". Atualmente tenta-se aproveitar tudo o que seja pertinente à nossa realidade de ensino. Segundo Marques, (2011, p.23) a abordagem de ensino está mais abrangente e não se limita mais a aceitar um único método. A tabela 1, a seguir, apresenta 
um panorama dos diversos métodos e abordagens de ensino-aprendizagem de língua estrangeira.

Tabela 1: Visão esquemática dos métodos e abordagens de ensino de língua inglesa (Extraídos de RAPPAPORT, 2008, pp.92-95)

\begin{tabular}{|c|c|c|c|c|}
\hline $\begin{array}{c}\text { Método/ } \\
\text { abordagem }\end{array}$ & $\begin{array}{c}\text { Teoria da } \\
\text { aprendizagem da } \\
\text { língua }\end{array}$ & $\begin{array}{l}\text { Objetivos } \\
\text { linguísticos }\end{array}$ & Conteúdo & $\begin{array}{c}\text { Tipos de } \\
\text { atividades }\end{array}$ \\
\hline $\begin{array}{l}\text { Método de } \\
\text { tradução } \\
\text { gramatical }\end{array}$ & Não há teoria & $\begin{array}{l}\text { Treinamento e } \\
\text { desenvolvimento } \\
\text { intelectual. }\end{array}$ & $\begin{array}{l}\text { Uma lista de } \\
\text { regras } \\
\text { gramaticais a } \\
\text { serem } \\
\text { aprendidas. }\end{array}$ & $\begin{array}{l}\text { Aplicação correta e } \\
\text { precisa de regras } \\
\text { gramaticais para } \\
\text { poder traduzir } \\
\text { sentenças. }\end{array}$ \\
\hline Método direto & $\begin{array}{l}\text { Não há teoria, mas } \\
\text { parte do pressuposto } \\
\text { de que a aquisição de } \\
\text { L2 pode ser "natural" } \\
\text { como a de LI. }\end{array}$ & $\begin{array}{c}\text { Proficiência oral, } \\
\text { precisão (auditiva e } \\
\text { de produção oral), } \\
\text { pronúncia e uso da } \\
\text { gramática. }\end{array}$ & $\begin{array}{c}\text { Expressões, } \\
\text { vocabulário e } \\
\text { estruturas do } \\
\text { dia a dia. }\end{array}$ & $\begin{array}{c}\text { Perguntas e } \\
\text { respostas. }\end{array}$ \\
\hline $\begin{array}{c}\text { Método } \\
\text { audiolingual }\end{array}$ & $\begin{array}{c}\text { Behaviorismo } \\
\text { (formação de hábito), } \\
\text { imitação e repetição. }\end{array}$ & $\begin{array}{l}\text { Pronúncia e } \\
\text { estruturas. }\end{array}$ & $\begin{array}{l}\text { Estruturas } \\
\text { gramaticais } \\
\text { ordenadas por } \\
\text { grau de } \\
\text { dificuldade e } \\
\text { seqüenciais. }\end{array}$ & $\begin{array}{c}\text { Exercícios de } \\
\text { substituição } \\
\text { (drills), repetição e } \\
\text { jogos. }\end{array}$ \\
\hline $\begin{array}{c}\text { Abordagem } \\
\text { comunicativa }\end{array}$ & $\begin{array}{l}\text { Não há teoria, mas } \\
\text { pressupõe que "se } \\
\text { aprende fazendo". }\end{array}$ & $\begin{array}{l}\text { Competência } \\
\text { comunicativa. }\end{array}$ & $\begin{array}{l}\text { Estruturas, } \\
\text { funções e } \\
\text { noções. }\end{array}$ & $\begin{array}{l}\text { Grande variedade } \\
\text { de formas de } \\
\text { exercícios. }\end{array}$ \\
\hline $\begin{array}{c}\text { Abordagem } \\
\text { natural }\end{array}$ & $\begin{array}{c}\text { Teoria Complexa } \\
\text { sobre as condições e } \\
\text { processo de } \\
\text { aprendizagem. }\end{array}$ & $\begin{array}{l}\text { Dependem das } \\
\text { necessidades do } \\
\text { aluno. }\end{array}$ & $\begin{array}{l}\text { Estruturas e } \\
\text { vocabulário. }\end{array}$ & $\begin{array}{l}\text { Mímica, fotos, } \\
\text { gravuras, audição e } \\
\text { demais materiais } \\
\text { comunicativos. }\end{array}$ \\
\hline $\begin{array}{c}\text { Método de } \\
\text { aprendizagem } \\
\text { em grupo }\end{array}$ & $\begin{array}{l}\text { São considerados } \\
\text { processos e condições } \\
\text { de aprendizagem. }\end{array}$ & Proficiência oral. & $\begin{array}{l}\text { Depende do } \\
\text { que o aluno } \\
\text { deseja } \\
\text { comunicar. }\end{array}$ & $\begin{array}{c}\text { Conversações entre } \\
\text { alunos são } \\
\text { gravadas e } \\
\text { transcritas para } \\
\text { posterior análise } \\
\text { formal da língua. }\end{array}$ \\
\hline $\begin{array}{c}\text { Método } \\
\text { silencioso }\end{array}$ & $\begin{array}{c}\text { Processos e } \\
\text { condições de } \\
\text { aprendizagem são } \\
\text { importantes. }\end{array}$ & $\begin{array}{c}\text { Habilidades } \\
\text { auditivas de } \\
\text { produção oral. }\end{array}$ & $\begin{array}{l}\text { Gramática e } \\
\text { vocabulário. }\end{array}$ & $\begin{array}{l}\text { Quadros para } \\
\text { suporte visual e } \\
\text { memorização. }\end{array}$ \\
\hline
\end{tabular}

Para os objetivos deste trabalho, abordamos a seguir apenas os principais métodos que tiveram destaque no ensino de LE, ao longo da história. Um olhar atento para essas mudanças nos métodos e abordagens é relevante, pois, segundo Gense (2011, p.30), as transformações dessas abordagens mostram a mudança de perspectiva sobre o que significa a fluência desejada dos alunos.

O método de tradução gramatical, também conhecido como Grammar translation method, é o mais antigo e consistia em fornecer aos alunos um conjunto de regras 
gramaticais, memorização de palavras e tradução de sentenças muitas vezes descontextualizadas. Segundo Leffa, $(1998$, p.4) o professor fornece ao aluno vocabulário e regras gramaticais, considerando que quanto maior o domínio de regras, maior a habilidade para leitura e escrita, e quase nunca os estudantes são estimulados para desenvolverem a habilidade oral.

O método direto surgiu como uma reação adversa ao método de tradução gramatical, por considerar que não estavam sendo enfatizadas as habilidades de fala e audição. Segundo Rapaport (2008, p. 69) a ênfase passou a ser na oralidade e na exatidão da pronúncia. O professor formulava perguntas que necessitavam de respostas. Não havia menção à língua materna.

O método audiolingual ou audiolingual method consiste em estruturas gramaticais ordenadas seguindo um grau crescente de dificuldade. Entende-se que há uma ordem natural para a aprendizagem das habilidades: audição, fala, leitura e escrita, nesta ordem. A pronúncia é ensinada desde o início, e a escrita e a leitura baseiam-se no trabalho com a oralidade. De acordo com Gense, (2011, p.32) no método audiolingual a língua é considerada como um conjunto de estruturas, portanto deve ser apresentada por meio de diálogos que devem ser imitados e repetidos. Maciel (online, p. 07), diz que esse método nasceu com base no estruturalismo americano e na psicologia behaviorista, tendo como objetivo principal levar o aluno a comunicar-se na língua-alvo através da formação de novos hábitos linguísticos.

A abordagem comunicativa, segundo Rapaport, (2008, p. 73) surgiu por duas razões. A primeira foi a insatisfação com a teoria estruturalista. Além disso, houve aumento considerável de adultos, na Europa, com necessidades específicas de aprendizagem de uma língua estrangeira. Os objetivos para o ensino-aprendizagem passaram a envolver as quatro habilidades linguísticas (audição, fala, leitura e escrita) em contextos mais verossímeis de uso. Essa abordagem tem por base o aprender fazendo. Leffa, (1988, p. 22) afirma que "um dos aspectos mais criticados pela abordagem comunicativa em relação às abordagens antigas foi a falta de objetivos específicos no ensino de línguas".

De acordo com Vilaça (2008, p. 81) a falta de uma abordagem específica para o ensino de língua estrangeira abriu margem para o ecletismo de abordagens, métodos, técnicas e ferramentas utilizadas em sala de aula, visto que, o desenvolvimento de novos 
métodos não significou o fim de problemas relacionados ao processo de ensino aprendizagem.

Duas das autoras da presente pesquisa observaram em seus estágios em escolas públicas do ensino fundamental que o que parece ser prática recorrente no ensino de língua estrangeira é dar a ênfase nas atividades de repetição de estruturas gramaticais, sem muita contextualização, principalmente através de exercícios escritos. Essa percepção é corroborada por Miccoli (2007, p. 56) ao afirmar que

a dificuldade de se trabalhar com as quatro habilidades é uma experiência comum aos professores, que não conseguem principalmente implementar atividades para o desenvolvimento das habilidades de escuta e fala adequadas ao número de alunos em sala de aula .

Devido à crescente importância do conhecimento de línguas na atualidade, acreditamos ser cada vez mais necessário o desenvolvimento da habilidade oral e, por isso, é preciso a oportunidade de praticar a língua estrangeira estudada. Mas um ensino repetitivo de palavras ou a mera memorização de regras gramaticais pode resultar no desinteresse do aprendiz, o qual acaba não vendo sentido em aprender uma língua estrangeira.

Também consideramos importante trabalhar com a oralidade no início do sexto ano do ensino fundamental, pois muitos alunos começam a entrar em contato com uma segunda língua nesta fase escolar. Por se tratar de uma novidade para a maioria dos alunos, pode ser que o interesse pelos estudos da LE seja maior se desde o início ele for exposto a situações em que a língua falada seja utilizada.

Os próprios PCN-LE (1998, p.54), orientam que o professor aproveite essa novidade para desenvolver a habilidade oral dos alunos com atividades dinâmicas. Então, apesar das condições não favoráveis ao ensino de língua estrangeira na maioria das salas de aula, acreditamos que "o professor pode criar uma atmosfera lúdica, espontânea e contextualizada, a fim de que seus alunos façam produções orais mais significativas para melhorarem sua fluência" (SILVA, 2012, p.11).

O interesse dos alunos em estudar uma língua diferente da materna é fundamental para determinar o sucesso na aprendizagem, pois faz com que se mantenham direcionados ao que deve ser aprendido. Afinal de contas, segundo Marques (2011, p.32) nosso cérebro esforça-se para aprender quando ocorrem pensamentos significativos, pois tudo o que é chato e sem sentido faz nosso pensamento voar. 
De acordo com Vilaça (2008, p.85) “o professor precisa estar cada vez mais preparado para não só lecionar, mas também administrar o processo de ensinoaprendizagem de uma língua estrangeira." Assim, o processo de ensino-aprendizagem da língua inglesa exige preparo e dedicação do professor.

Concordamos com Parolin quem nos diz que

\begin{abstract}
ensinar é uma atividade de um profissional chamado "professor" que tem como tarefa direcionar um aprendiz. Para ensinar, esse profissional necessitará preparar-se e planejar, a fim de promover as intervenções necessárias, os encaminhamentos que o momento necessite e as avaliações que irão fazer as correções dos rumos tomados. $\mathrm{O}$ verbo "ensinar" deveria rimar sempre com motivar, desafiar, oportunizar, vivenciar, avaliar, acertar, errar, retornar, recomeçar e acertar! (PAROLIN, 2008, p.30, apud MARQUES, 2011, p. 26).
\end{abstract}

Portanto, ensinar não é apenas transmitir conhecimentos, obedecendo a determinadas metodologias, é fazer com que o aluno se comprometa, é criar condições para que os alunos desenvolvam suas habilidades. Nesse contexto podemos trazer a fala de Almeida Filho (2008, p. 13), quem nos lembra que "a operação global de ensinar uma língua estrangeira compreende o planejamento de cursos e suas unidades, a produção ou seleção criteriosa de materiais, a escolha e construção de procedimentos para experienciar a língua-alvo." Logo, a afirmação do autor só reforça a importância da adequação e do planejamento adequado, os quais contribuirão para que o aluno vivencie a língua de fato.

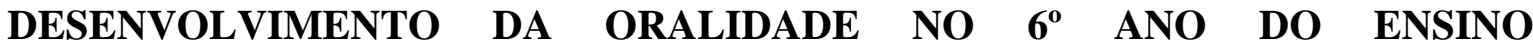 FUNDAMENTAL
}

Nesta seção, discutimos como o aluno de sexto ano do ensino fundamental pode ser levado a produzir enunciados significativos na língua estrangeira.

\section{Atividades de produção oral}

Conforme mencionamos anteriormente, para a maioria dos alunos, o contato com a aprendizagem de inglês ocorre no início do sexto ano do Ensino Fundamental, período em que eles também enfrentam significativas transformações emocionais e físicas. Em algumas áreas do Brasil, os alunos de LE nunca tiveram qualquer contato direto com outra língua estrangeira; em muitos casos, ele é o primeiro membro da família a iniciar essa experiência. Nesse contato inicial, acreditamos ser valioso o trabalho de apresentação de 
vocabulário e expressões práticas através de diálogos, textos diversos, figuras, mímicas, objetos reais, exemplos variados, etc.

Cremos que as pessoas aprendem a falar, falando. Assim, é preciso promover oportunidades de comunicação para que a oralidade seja desenvolvida. E para a fluência é preciso a prática. Phillips (1997, p.21) destaca que, quanto mais jovem o aprendiz, mais facilidade ele terá para realizar atividades em que o uso da língua envolve diretamente a oralidade.

Como primeiro contato com a Língua Inglesa, os alunos precisam de oportunidade para praticar o idioma, com o intuito de tornarem-se capazes de comunicar-se na língua estudada. Entendemos que essa comunicação pode se dar através de atividades como apresentação de textos para leitura e compreensão oral, ampliando vocabulário e estimulando ideias; discussão de notícias de jornal, propagandas e textos interessantes adequados à faixa etária desses alunos. No início, cremos ser necessário haver bastante repetição, propiciando aos alunos mais confiança e fluência. E os podcasts escolhidos para o trabalho com a turma refletirão esse foco. Com o uso dos podcasts nas aulas de língua estrangeira, o professor poderá aproveitar os recursos tecnológicos bastantes disponíveis e diversos atualmente (HADFIELD \& HADFIELD, 2009, p. 121.).

Santos e Negrão (online, p.16-19) elaboraram uma pesquisa com alunos do sexto ano do Ensino Fundamental com foco no desenvolvimento da produção oral e, assim, mostraram que é possível despertar o interesse pela língua, apresentando usos de metodologia com atividades de exercícios orais como a conversação, favorecendo o interesse dos alunos pela língua. A referida pesquisa permitiu avaliar que $70 \%$ dos alunos participantes ficaram motivados nas atividades de oralidade e 94,7\% consideraram ótimas as atividades de produção oral desenvolvidas.

Portanto, mais uma vez, destacamos a importância de as aulas de língua estrangeira terem também como foco o desenvolvimento da competência oral dos alunos. Afinal, como Ur (2004, p. 120) afirma, das quatro habilidades, falar parece ser a mais importante, pois quando alguém sabe uma língua é conhecido como falante daquela língua e muitos aprendizes de uma língua estrangeira têm interesse maior em aprender a falar a língua estrangeira que estão estudando. 


\section{O papel do professor}

É importante destacar o papel do professor na sala de aula dando mais ênfase à produção de significados do que formas gramaticais, promovendo materiais para incentivo ao aluno no pensar e interagir com a língua. Almeida Filho (2008, p. 51-52) aponta que do professor se esperará menos domínio nas atividades de aula, tornando os alunos mais ativos. $\mathrm{O}$ aluno têm coisas a perguntar, a dizer, a opinar e a questionar.

Planejar aulas diferenciais despertando a atenção dos alunos pelo idioma e transformar a sala em um ambiente seguro para que o aluno não tenha medo de arriscar e errar na pronúncia, como por exemplo, iniciar diálogos com frases simples para que a prática da oralidade se torne realidade diária em sala de aula, podem transformar a sala de aula em um espaço para se trabalhar a oralidade no ensino da língua. Para isso, o professor deve ter um bom conhecimento linguístico, ensinar a pronúncia da língua criando atividades e oportunidades para os alunos falarem a língua e ouvirem diversos sotaques na língua estrangeira. Complementamos também que o uso de material visual é importante na fixação de vocabulário e para prender a atenção dos alunos.

Entendemos, então, que um modelo de sala de aula interativa na qual os alunos troquem contato uns com os outros favoreça o desenvolvimento da habilidade oral. Dessa maneira, atividades que permitam que os alunos se expressem individualmente, em duplas, trios ou grupos pode beneficiar essa construção conjunta do conhecimento na língua estrangeira.

Alves de Jesus (online, p. 7) alerta também para a questão da cultura da correção de erros. Em demasia, isso pode prejudicar o desenvolvimento do aluno na prática oral do inglês impedindo-o de sentir-se confortável para emitir enunciados na língua estrangeira. $\mathrm{O}$ aluno aprende a falar a língua em um ambiente seguro, amistoso, para que possa produzir o mais espontaneamente possível.

É produtivo promover o diálogo, incentivar cumprimentos na entrada e saída da sala, pedir que os estudantes falem sobre seu dia, o que fizeram até então, ou no fim de semana, se viram algum filme interessante, ou falarem sobre algum fato em evidência na mídia, enfim despertar a curiosidade.

É inegável que, no ambiente de ensino de língua estrangeira, os professores precisam utilizar o máximo possível a língua ensinada para que os alunos se acostumem a ouvir e se arrisquem a falar. Segundo Schimitz (2009, p.17) 
se o profissional de língua estrangeira não fizer uso do idioma na sala de aula, ele estará abrindo mão da qualificação que mais o caracteriza e distingue de professores de outras matérias: a sua condição de ser bilíngue, de poder transitar entre duas culturas, a materna e a estrangeira.

O complemento de todo esse processo educacional exige do professor não apenas uma boa formação acadêmica, desenvoltura e domínio da língua, mas também ousadia e consciência da habilidade de ensinar, desenvolvendo as quatro habilidades: ouvir, falar, ler e escrever para uma realização plena do ensino.

Os PCN-LE (1998, p.8) apontam os seguintes objetivos para o ensinoaprendizagem de uma LE:

\footnotetext{
$\checkmark$ Expressar e comunicar suas idéias, interpretar e usufruir das produções culturais, em contextos públicos e privados, atendendo a diferentes intenções e situações de comunicação;

$\checkmark$ Saber utilizar diferentes fontes de informação e recursos tecnológicos para adquirir e construir conhecimentos;

$\checkmark$ Questionar a realidade formulando-se problemas e tratando de resolvê-los, utilizando para isso o pensamento lógico, a criatividade, a intuição, a capacidade de análise crítica, selecionando procedimentos e verificando sua adequação.
}

Baseados nestes objetivos os professores podem rever metodologias e praticar as orientações referidas em sala de aula. Sabemos que, toda vez que ocorrem mudanças, elas levam algum tempo para serem absorvidas e postas em prática. Nesse caso, o desenvolvimento da habilidade oral em sala de aula não será algo que acontecerá imediatamente. Porém, é necessário que comecemos de algum ponto, a fim de fazer com que o ensino-aprendizagem de LE nas nossas salas de aula no ensino fundamental seja algo realmente significativo para os alunos.

\section{PODCASTS E O DESENVOLVIMENTO DA HABILIDADE ORAL}

O podcast é uma das mais recentes configurações entre os formatos sonoros disponíveis na Web. Junção da palavra Ipod (MP3player da Apple) e broadcasting (transmissão em rede), o gênero surgiu em 2004 e consiste em um arquivo sonoro disponibilizado em um site. Esse arquivo pode ser produzido pelo usuário. Feito o download, pode-se ouvir o conteúdo diretamente pelo programa ou transferi-lo para um mp3 player, (Ipod, celulares etc.), para audição posterior onde e quando se desejar.

O formato mp3 foi desenvolvido em 1989 por engenheiros alemães, mas só em 1997 foi disponibilizado o primeiro software de reprodução de arquivos, permitindo, 
assim, que até os áudios de livros pudessem ser baixados. Hoje esse dispositivo já faz parte do cotidiano de muitos alunos, além de ter um preço acessível a todos. Lembramos que há outros formatos de arquivos para se produzir podcasts e destacamos o papel da Internet para a popularização dos podcasts. Não é necessário ter um mp3 player para se ouvir podcasts. O ideal é que eles sejam ouvidos diretamente de sites da Internet, principalmente porque há muitos sites em que os podcasts são acompanhados de imagens que facilitam a compreensão ou apresentam o áudio de modo mais contextualizado. Contudo, sabemos que, em muitas escolas, o acesso à internet ainda é bastante precário. Então, se for este o caso, o professor pode baixar os arquivos de áudio da internet e leva-los à sala em formato compatível com os aparelhos disponíveis na escola.

Dentre as finalidades do uso de podcasts para aprendizagem de línguas estrangeiras identificadas por Furtoso \& Gomes (2011, p. 1044) destacam-se a revisão de vocabulário, as entrevistas com falantes nativos e os exercícios de compreensão oral. Esses autores também apontam a existência de outra faceta de uso do podcast para o aprendizado de LE, que é a do aluno criar o seu próprio podcast, pois além de desenvolver a habilidade de compreensão oral do estudante, melhora a sua fluência.

A tabela 2, abaixo, apresenta objetivos e possíveis atividades identificadas por essas autoras para desenvolvimento da oralidade, com a produção de podcast em contexto de ensino-aprendizagem em língua estrangeira. Podemos perceber que a criação do podcast é uma atividade que permite que o aluno utilize a linguagem falada em um contexto real de uso. Ele pode gravar mensagens de apresentação para a turma, ler textos, comunicar-se com pessoas de outros países, entre uma infinidade de possibilidades de uso desse recurso.

Ao gravar e ouvir as gravações dos colegas, professor e outros podcasts disponíveis na internet, o aluno pode perceber questões como entonação, ritmo, junção de palavras etc., o que facilita a apreensão da habilidade oral.

Tabela 2: Adaptação da tabela de objetivos da produção de podcasts em LE (FURTOSO \& GOMES, 2011, p. 1048)

\begin{tabular}{|c|c|c|}
\hline $\begin{array}{l}\text { Produtores do } \\
\text { podcast }\end{array}$ & Objetivos & Exemplos possíveis \\
\hline Alunos & $\begin{array}{l}\text { Desenvolvimento da proficiência oral tendo em vista o } \\
\text { feedback do professor com funções avaliativas. } \\
\text { Estabelecimento de contato com outros alunos } \\
\text { geograficamente distantes. }\end{array}$ & $\begin{array}{l}\text { Gravação da leitura de um texto } \\
\text { fornecido pelo professor. } \\
\text { Gravação de uma mensagem de } \\
\text { apresentação pessoal do aluno. }\end{array}$ \\
\hline Pro & $\begin{array}{l}\text { Disponibilizar conteúdos em formatos alternativos e } \\
\text { passíveis de utilização em dispositivos móveis de uso } \\
\text { comum. (leitores de MP3, e etc.). } \\
\text { Disponibilizar exemplos de expressão oral em língua }\end{array}$ & $\begin{array}{l}\text { Gravação de um texto do manual } \\
\text { escolar, lido pelo professor. } \\
\text { Gravação de leituras de artigos de } \\
\text { jornais em língua estrangeira. }\end{array}$ \\
\hline
\end{tabular}




\begin{tabular}{|l|l|l|}
\hline & $\begin{array}{l}\text { estrangeira. } \\
\text { Dar feedback individualizado sobre a produção (oral e } \\
\text { escrita) dos alunos. }\end{array}$ & $\begin{array}{l}\text { Gravação de } \\
\text { individualizado sobre a produção dos } \\
\text { alunos. }\end{array}$ \\
\hline $\begin{array}{l}\text { Pedigir em conjunto textos e fazer sua locução, } \\
\text { promovendo a colaboração e cooperação entre } \\
\text { alunos }\end{array}$ & $\begin{array}{l}\text { Gravação de um texto sobre a } \\
\text { localidade onde se situa a escola e } \\
\text { estudantes e destes com o professor. } \\
\text { Promover o conhecimento de culturas associadas à a professores e estudantes } \\
\text { língua em estudo através da troca de documentos } \\
\text { produzidos. }\end{array}$ & $\begin{array}{l}\text { da língua em estudo. } \\
\text { de países, falantes }\end{array}$ \\
\hline
\end{tabular}

Percebemos que os objetivos apontados na tabela 2 se coadunam muito mais com a abordagem comunicativa, explicitada na tabela 1, anteriormente. Contudo, gostaríamos de enfatizar que não será apenas um método que vai nortear a escolha e o trabalho com podcasts. Conforme destacamos na tabela 1, o método a ser escolhido dependerá dos objetivos linguísticos a serem alcançados. Podemos, em alguns momentos, objetivar a fixação de estruturas, principalmente com alunos iniciantes, assim, as características do método audiolingual se farão mais presentes, por exemplo. Contudo, convém ressaltar que acreditamos ser primordial o desenvolvimento da proficiência oral e, desta maneira, talvez a abordagem comunicativa prevaleça nas atividades propostas. Há momentos em que os alunos podem fazer as atividades sozinhos, outros em que atividades em grupos devem prevalecer. Ou atividades cujo foco seja a exposição e repetição de estruturas gramaticais e outras em que o objetivo seja a produção oral mais elaborada.

No que se refere ao uso de podcasts em contextos reais de ensino, Souza (2007, p. 17) relata um projeto no qual Moura \& Carvalho (2006) utilizaram podcasts em aulas de línguas como forma de motivação dos alunos. Esse projeto europeu entre alunos belgas e portugueses resultou em um site, fóruns de discussão dos temas do cotidiano, blog, chats e também um podcast, que inovou por possibilitar a distribuição do arquivo de áudio, texto e imagem na internet. Segundo as referidas autoras, para agregar todo esse material tecnológico do projeto foi necessário uma colaboração total entre professores e alunos.

Através do podcast foi possível levar os alunos a desenvolver e a aperfeiçoar a competência linguístico/comunicativa da compreensão e da expressão escrita e oral, de modo a facilitar a comunicação em qualquer situação. Esta iniciativa possibilitou, ainda, o encontro com outra cultura e sua compreensão (MOURA e CARVALHO, 2006, p.92).

Utilizar o áudio com a finalidade de ensinar uma língua estrangeira não é nenhuma novidade, já que as fitas cassetes e o CD-ROM, por exemplo, há muito fazem parte do contexto educacional, mas segundo Carvalho et al (2009, p.2 apud PAULA, 2010, p.13) podcast é o "renascimento do áudio para fins educativos" e pode vir a substituir o CD- 
ROM que geralmente acompanha alguns livros didáticos, à medida que se verifica a existência do mp3, um dispositivo móvel de áudio, mais fácil, confiável, de maior portabilidade, com possibilidade de gravar, avançar, retroceder e reproduzir quantas vezes forem necessárias para melhores resultados de aprendizado.

\section{O uso do podcast no $6^{\circ}$ ano do ensino fundamental}

Propomos o uso de podcasts logo nesta fase inicial de contato com a língua estrangeira, com o intuito de desenvolver a habilidade oral para que os alunos terminem o ensino fundamental com a capacidade de comunicarem-se em contextos básicos de interação.

Moura e Carvalho (2006) concluíram que os podcasts são uma ferramenta excelente no ensino de LE, pois permitem aos alunos a prática da oralidade e a audição da pronúncia correta. E nosso foco neste trabalho é verificar a possibilidade da prática oral através do uso do podcast.

Na prática, ao longo das aulas, algumas atividades desde a simples compreensão oral audição até a produção de seus próprios podcasts, podem ser adaptadas e direcionadas para facilitar e permitir o aprendizado do aluno. Inicialmente sugerimos atividades, focando o desenvolvimento oral, que envolvam conhecimento e interesse dos alunos na faixa etária alvo, com objetivo essencial de levá-los a se expressar na língua, adaptando-os em um ambiente que deve ser construtivo, conversacional e contextualizado.

Em um primeiro contato, os alunos podem apenas ser apresentados à ferramenta, para saberem o que é e para que serve, definir conceitos, visualizar funcionamento, ou indicar fontes mostrando quais tipos de atividades podem ser feitas com o podcast. E com objetivo de verificar a eficácia e a receptividade da ferramenta pode-se formular questionário para os alunos, objetivando saber como eles gostariam de utilizar o recurso em sala, pedindo sugestões, sondando se já estão familiarizados com podcasts e se gostam ou não de utilizá-los.

Em seguida a todo esse processo, é preciso ter consciência que as fontes de podcasts são variadas e os temas também. Então, precisamos optar por aquelas que tenham uma linguagem adequada para uma turma de sexto ano do Ensino Fundamental, ou seja, nível básico de vocábulos, e ainda contextos adequados para a faixa etária. 
A figura 3, abaixo, é a página inicial de um site que apresentamos como sugestão de atividades com o uso de podcasts com nossos alunos do sexto ano.

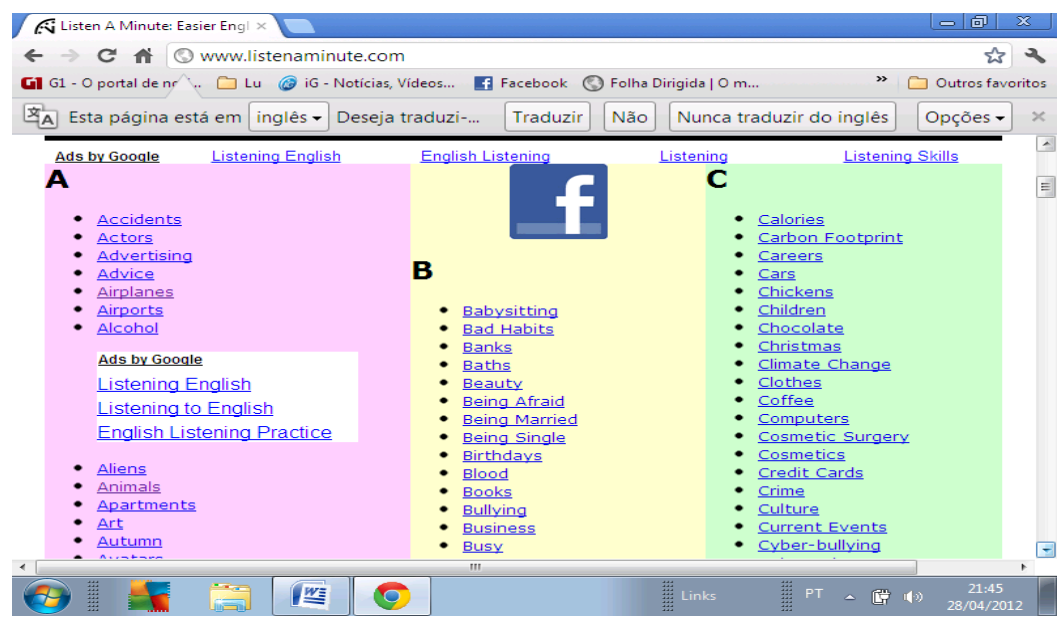

Figura 1: Home page do site www.listenaminute.com.br - opções variadas de podcasts

Este site oferece atividades e linguagem de nível básico, está dividido por temas e apresenta vários exercícios de compreensão. Logo nesta primeira página o site apresenta atividades com podcasts divididas por categorias ou assuntos, conforme figura 1.

A figura 2, abaixo, exemplifica a tela da categoria escolhida. Optamos pela categoria, "animals" para ilustrar.

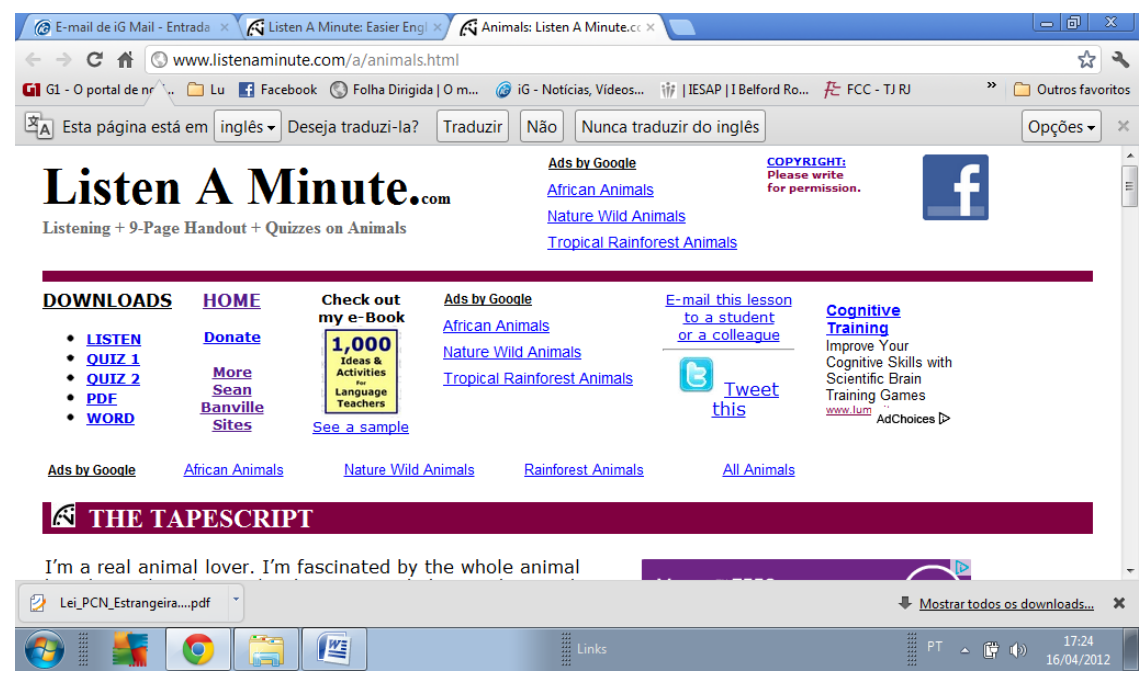

Figura 2: Página da atividade da categoria, "animals", escolhida (www.listenaminute.com.br) 
Podemos observar na figura 2, acima, que a tela apresenta algumas opções de atividade para download, tais como listen, quiz1, quiz2, PDF, Word. A figura 3, a seguir, é a página da atividade de podcast em si, chamada de listen no referido site.

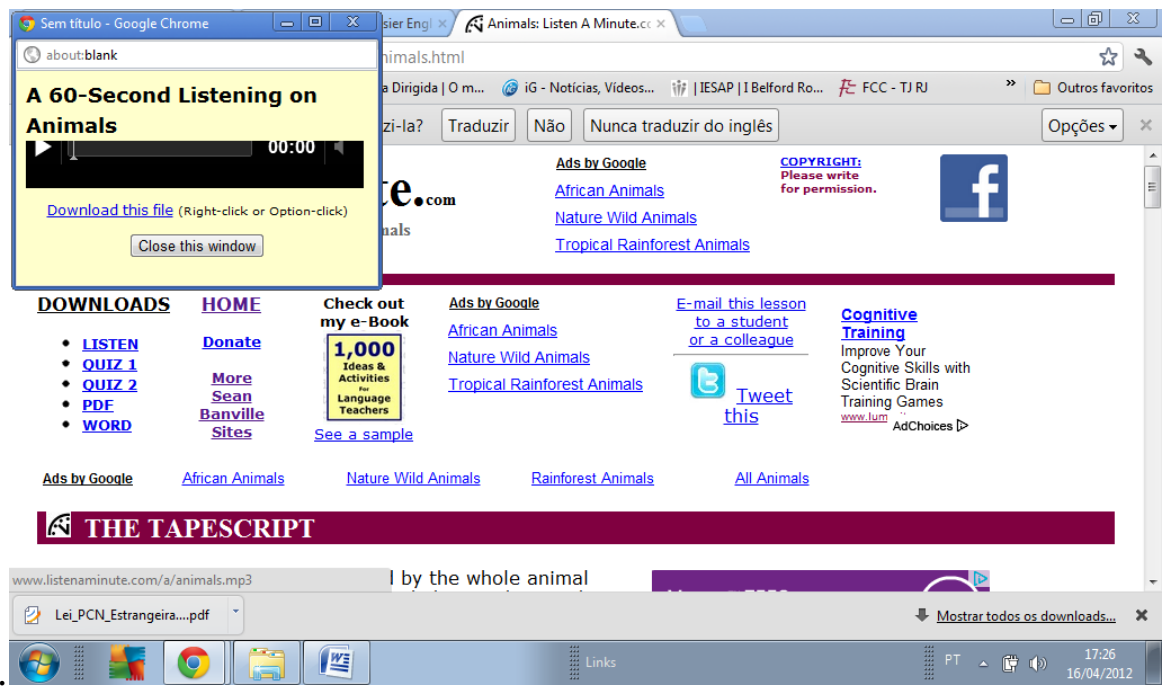

Figura 3: Página com a atividade listen/podcast selecionada (www.listenaminute.com.br)

Uma atividade que sugerimos para trabalhar a oralidade seria o aluno ouvir o podcast primeiramente sem o texto e depois fazendo a leitura em voz alta. Entendemos que essa repetição treina e exercita a expressão e a oralidade do aluno na língua inglesa. $\mathrm{O}$ professor pode, ainda através do texto do podcast, observar os novos vocábulos, formular perguntas, estimulando respostas, incentivando a expressão oral e memorização da pronúncia.

Através do site sugerido entendemos que todas essas atividades, envolvendo a tecnologia podcast podem ser adaptadas pelo professor à turma para quem está lecionando. Estas possibilidades de atividades mostram a extensão da utilização dos podcasts. Entendemos que os podcasts educacionais privilegiam em particular a oralidade, elemento fundamental no ensino-aprendizagem de uma língua estrangeira.

Outro site, sugerido abaixo, oferece atividades com áudios (podcasts) para desenvolvimento da habilidade oral no nível do sexto ano do ensino fundamental. Trabalha vocabulários, diálogos iniciais e cotidianos, com muitas imagens e cores, conforme ilustra a figura 4 , em seguida. 


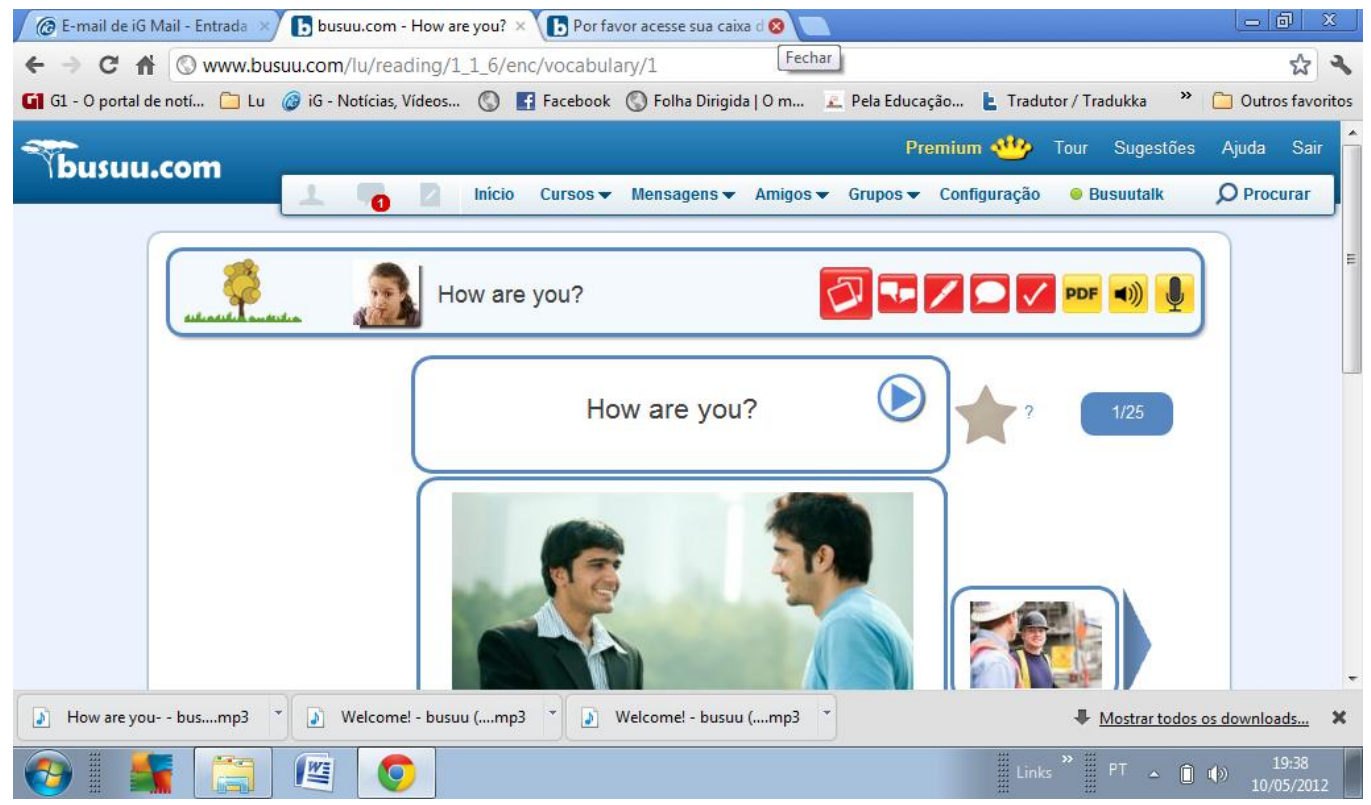

Figura 4: Atividades de desenvolvimento da habilidade oral da língua inglesa, nível iniciantes. (www.busuu.com)

Na figura 4, apresentamos a página inicial de um diálogo simples e cotidiano que o referido site oferece. Neste caso, trata-se de cumprimentos pessoais. Esse podcast pode ser apresentado em sala de aula ou acessado de casa, principalmente se a escola não dispõe de recursos tecnológicos necessários para o uso do podcast em sala de aula.

Nas figuras 5 e 6, abaixo, podemos visualizar alguns diálogos dos podcasts do referido site, a fim de termos uma ideia do que os alunos podem fazer. Eles podem ouvir e repetir sozinhos, ou o professor pode fazer role plays, atividades em que os alunos dramatizam o diálogo para a turma ou em pequenos grupos.

Caso o aluno tenha dificuldade com a compreensão, ele pode clicar no recurso de ver a tradução também, a fim de compreender plenamente o que está repetindo. Contudo, o ideal é que ele entenda o contexto de uso e não crie dependência no recurso de tradução para poder compreender um texto. 


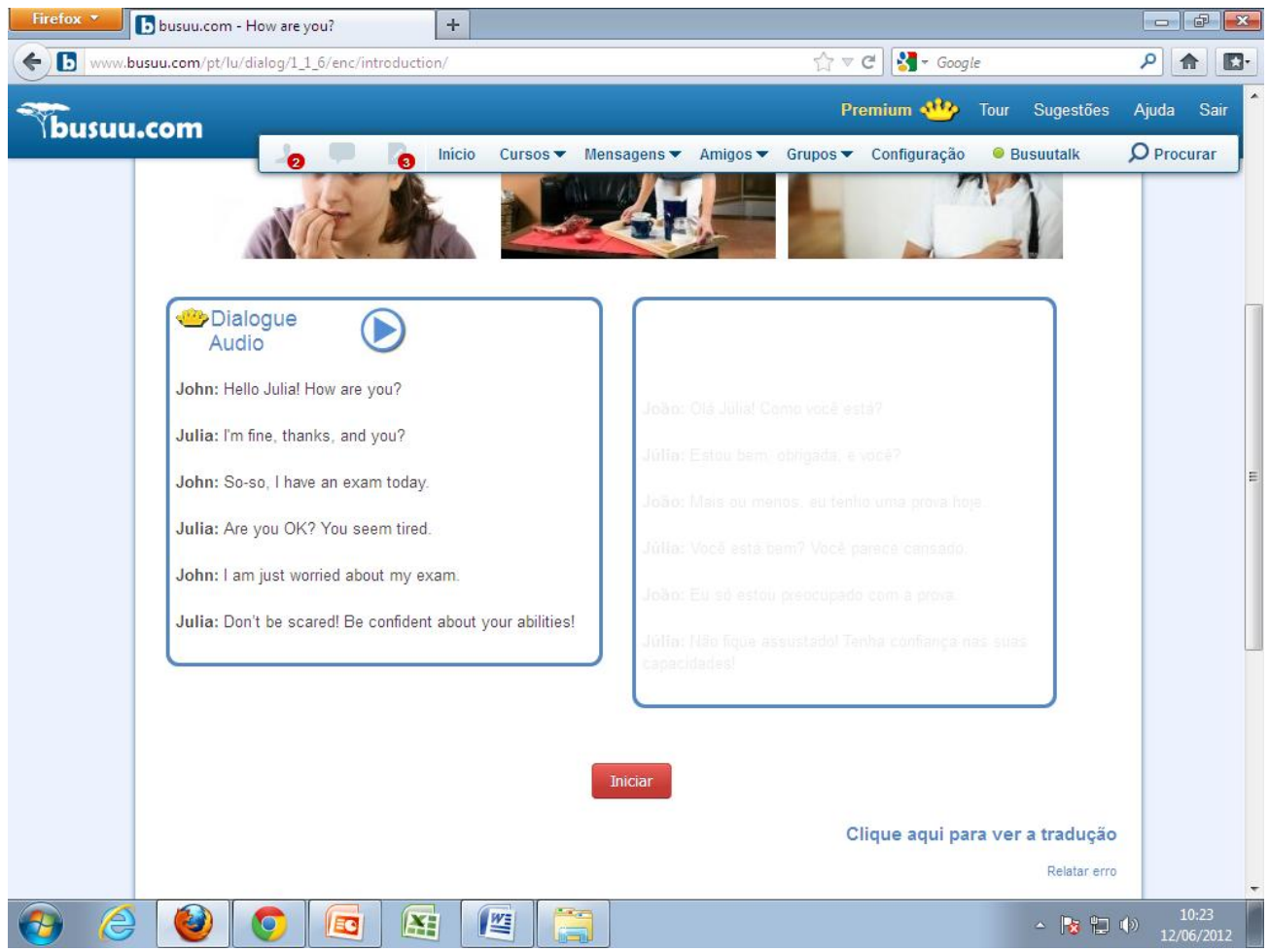

Figura 5: Visualização do diálogo do podcast "How are you” (www.busuu.com)

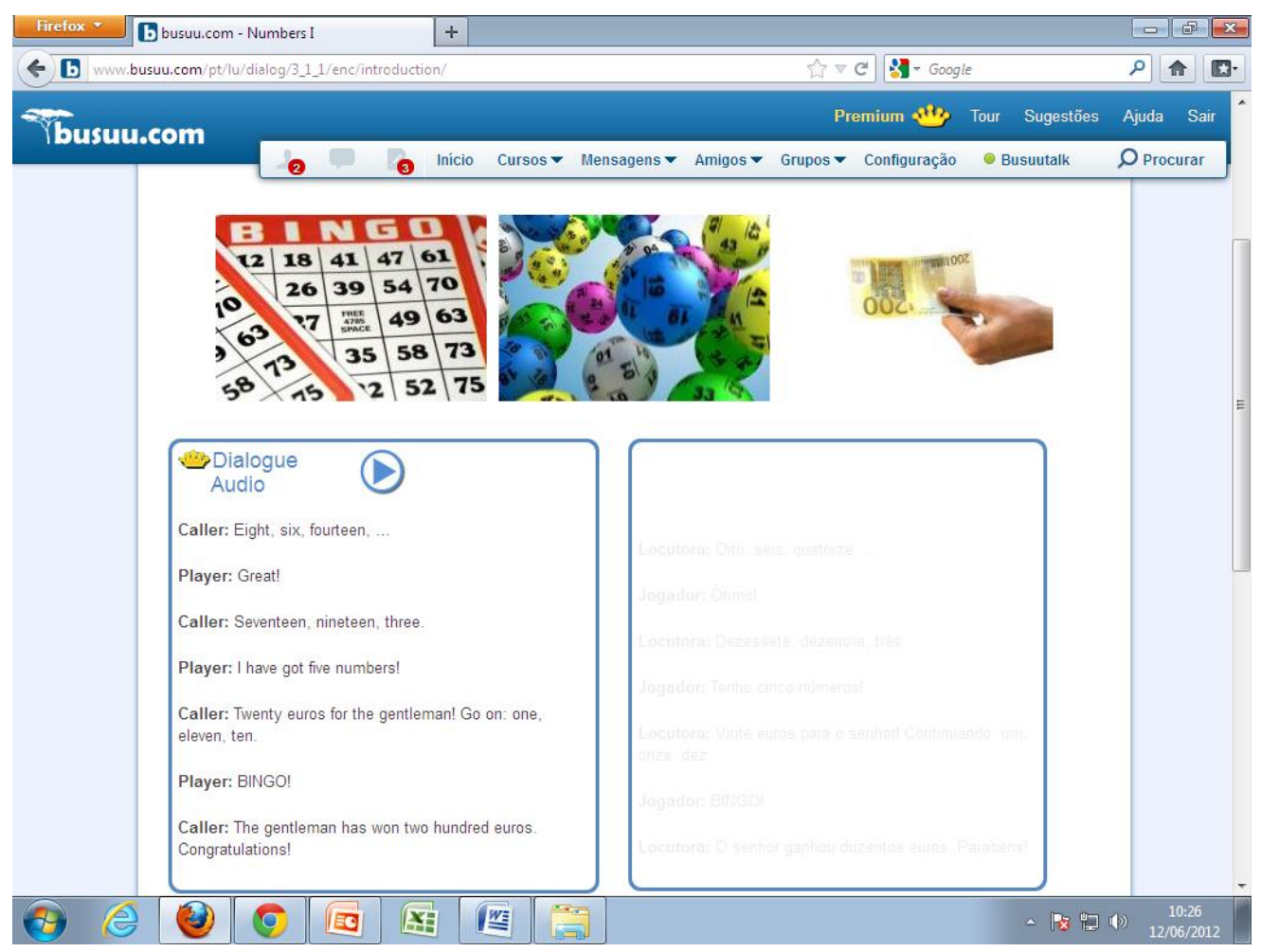

Figura 6: Visualização do diálogo do podcast “Numbers” (www.busuu.com)

O site acima tem inúmeros podcasts com diálogos para a faixa etária inicial, além das categorias citadas, como por exemplo, cores, partes do corpo, horas, entre outros. 
Poderíamos relacionar uma série de sites com a ferramenta podcast para serem utilizados com fins educacionais, mas o objetivo deste artigo e o espaço não permitem. Nosso intuito foi mostrar brevemente uma forma inovadora no ensino de línguas e de que maneira esse recurso pode ser utilizado em nossas salas de línguas para desenvolver a competência oral dos nossos alunos.

\section{CONSIDERAÇÕES FINAIS}

Este artigo objetivou apontar a necessidade de se trabalhar o desenvolvimento da competência oral dos alunos nas aulas de língua inglesa desde o momento que eles têm contato com a língua estrangeira.

Com os recursos disponíveis com o advento das novas tecnologias, julgamos que propor atividades que lancem mão de recursos digitais para os alunos do sexto ano do ensino fundamental pode favorecer espaços significativos para o desenvolvimento da habilidade oral.

Apresentamos sugestões de como trabalhar na prática o desenvolvimento da oralidade dos alunos dentro e fora da sala de aula utilizando o podcast como recurso pedagógico, com atividades voltadas para o ensino na faixa etária dos alunos do sexto ano, geralmente de 10 a 12 anos, mas que podem ser adaptadas para alunos cujas idades não se coadunam com a série que estão cursando.

Acreditamos que somente o ensino repetitivo de regras gramaticais pode resultar no desinteresse do aprendiz. Sendo assim, é fundamental que o professor conheça os métodos de ensino-aprendizagem variados, a fim de que possa utilizar uma abordagem eclética, na qual o professor pode extrair de cada método existente o que for necessário e criar sua própria abordagem de ensino tendo como base o seu contexto pedagógico.

Sugerimos neste artigo que se que os professores que não fazem uso do idioma em sala de aula talvez possam dificultar o aprendizado do aluno, pois mesmo tendo acesso aos recursos pedagógicos, diminuem consideravelmente a exposição do aprendiz à língua estrangeira estudada. Dessa forma, podem acabar contribuindo para a perpetuação de uma perspectiva negativa do ensino de línguas como algo ineficaz em nossas escolas. Ressaltamos também que os professores precisam estar atualizados sobre as novas tecnologias digitais que auxiliam no processo de ensino-aprendizagem, pois a nova geração está conectada e a presença destas já é uma realidade nas escolas. 
Esperamos que este trabalho contribua para a discussão das necessidades e possiblidades que o trabalho de desenvolver a competência oral em uma língua estrangeira envolve. Pesquisas futuras podem incluir a observação da aplicação prática das sugestões aqui apresentadas, a fim de analisar as interações ocorridas em sala e a perspectiva dos alunos com o trabalho realizado através do recurso de podcasts variados, principalmente aqueles que privilegiem a própria produção oral do aluno para compartilhar com seus colegas e demais pessoas na rede.

\section{REFERÊNCIAS BIBLIOGRÁFICAS}

Ábila, F. (2010). Novas tecnologias na educação - a escola formando a geração digital. Revista Aprendizagem Ano 4, $\mathrm{n}^{\circ} 20$.

Almeida Filho, J. C. P. (2008). Dimensões comunicativas no ensino de línguas. Campinas, Editora Pontes.

Alves de Jesus, A. P. (online) Oralidade da Língua Inglesa nas escolas públicas$2^{a}$ fase do ensino fundamental. Disponível em: http://www.unifan.edu.br/files/pesquisa/ORALIDADE\%20DA\%20L\%C3\%8DNGUA\%20 INGLESA $\% 20$ NAS $\% 20$ ESCOLAS $\% 20 \mathrm{P} \% \mathrm{C} 3 \% 9 \mathrm{ABLICAS}-$ $\% 202 \% \mathrm{C} 2 \%$ AA $\% 20$ FASE $\% 20$ DO $\% 20$ ENSINO $\% 20$ FUNDAMENTAL $\% 20$ \%20ANA\%20PAULA\%20ALVES.pdf. Acesso em 25 de janeiro de 2012.

Bedaque, P. (2010). “Por que ...e suas tecnologias”?. Revista Aprendizagem Ano 4, no 20.

BRASIL. Ministério da Educação. Secretaria de Ensino Fundamental. (1998). Parâmetros Curriculares Nacionais - Ensino Fundamental - Língua Estrangeira. Brasília, Ministério da Educação e Desportos.

- (2000). Parâmetros Curriculares Nacionais - Ensino Médio - Língua Estrangeira. Brasília, Ministério da Educação e Desportos.

BRASIL. (2000). Linguagens, Códigos e suas Tecnologias. (Parâmetros Curriculares Nacionais do Ensino Médio; volume 1, parte II). Secretaria de Educação Básica. Brasília, Ministério da Educação, Secretaria de Educação Básica.

Franco, C. de P. (online). A tecnologia no ensino de línguas: do século XVI ao XXI. Disponível em http://www.claudiofranco.com.br/textos/franco_magna.pdf. Acesso em 25 maio de 2012.

Freire, P. (1996). Pedagogia da Autonomia - Saberes necessários à prática educativa. São Paulo: Paz e Terra. 
Furtoso, V.; Gomes, M. J. (online) Aprendizagem e avaliação da oralidade em contextos online - o potencial dos serviços de podcasting. Disponível em http://repositorium.sdum.uminho.pt/bitstream/1822/12854/3/gomes-viviane.pdf. Acesso em 22 de abril de 2012.

Gense, J. M. C. (2011). O ensino de língua inglesa no uso de portais de conteúdo para construção de ambientes de aprendizagem. Disponível em www.4.fct.unesp.br/pos/educacao/teses/2011/diss juliana.pdf. Acesso em 29.04.2012.

Hadfield, J.; Hadfield, C. (2009). Manual Oxford de Introdução ao Ensino da Língua Inglesa. Tradução de Sueli Monteiro, Editora Positivo.

Leffa, V. J. A. (1999). O ensino de línguas estrangeiras no contexto nacional. Contexturas, APLIESP, n. 4, p. 13-24. Disponível em http://www.leffa.pro.br/textos/trabalhos/oensle.pdf em 12 de abril de 2012. Acesso em 10 de abril de 2012.

. (online). Aprendizagem de línguas mediada por computador. Disponível em: http://www.leffa.pro.br/textos/trabalhos/B_Leffa_CALL_HP.pdf. Acesso em 28 de abril de 2012.

(1998). Metodologia do Ensino de Línguas. In BOHN, H.I, VANDRESEN, P. Tópicos em Linguistica aplicada: o ensino de línguas estrangeiras. Florianópolis: Ed. Da UFSC.

Maciel, K. D. (online). Métodos e abordagens de ensino de língua estrangeira e seus princípios teóricos. Disponível em:

http://www.apario.com.br/index/boletim34/uterrichtspraxis-metodos.doc. Acesso em 13 de março de 2012.

Marques, F. S. (2011). Ensinar e aprender Inglês: O processo comunicativo em sala de aula. Curitiba, Editora IBPEX.

Micolli, L. (2007). Experiências de Professores no Ensino de Língua Inglesa: uma categorização com implicações para o ensino e a pesquisa. UFMG. Linguagen e Ensino V.10, p.47-86, janeiro/julho.Disponível em:

www.rle.ucpel.br/index.php/rle/article/download/155/122 Acesso em 12 de junho de 2012.

Moura, A.; Carvalho, A.A. (2006). Podcast: Uma Ferramenta para Usar Dentro e Fora da Sala de Aula. Disponível em http://ubicomp.algoritmi.uminho.pt/csmu/proc/moura147.pdf. Acesso em 12 de maio de 2012.

(2006). Podcast: Potencialidades na Educação. Disponível em http://revistas.ua.pt/index.php/prismacom/article/viewFile/623/pdf. Acesso em 12 de maio de 2012.

Oliveira, A. S.; Cardoso, E. L. (online). Novas Perspectivas no Ensino da Língua Inglesa: Blogues e Podcasts. Disponível em http://www.eft.educom.pt. Acesso em 10 de fevereiro de 2012. 
Paiva, V. L. M. O. (online). O uso da Tecnologia no Ensino de Línguas Estrangeiras: breve retrospectiva histórica. Disponível em http://www.veramenezes.com/techist.pdf. Acesso em 28 de abril de 2012.

Paula, J. B. C. Podcasts educativos: possibilidades, limitações e a visão de professores de ensino superior. Disponível em http://www2.et.cefetmg.br/permalink/19843ce4-a3e111df-aeaa-00188be4f822.pdf. Acesso em 26 de maio de 2012.

Phillips, S. (1997). Young Learners. Oxford: Oxford University Press.

Rapaport, R. (2008). Comunicação e Tecnologia no ensino de línguas. Curitiba: Editora IBPEX.

Santos, P. R. dos \& Negrão, J. (2012). Compreensão e Produção Oral em Aulas de Inglês. Disponível em http://www.diaadiaeducacao.pr.gov.br/portals/pde/arquivos/1752-8.pdf. Acesso em 29 de abril de 2012.

Schimitz. J. R. (2011). A relação entre ansiedade e o desenvolvimento da competência oral em língua estrangeira. Disponível em http://cutter.unicamp.br. Acesso em 02 de janeiro de 2011.

Silva, S.P. (2012). Dinâmicas e jogos para aulas de idiomas. Petrópolis, RJ. Vozes.

Souza, S. A. de. (2012). Podcasting: uma ferramenta da mídia eletrônica no ensino de língua estrangeira. Disponível em www.calen.ct.utfpr.edu.br/monografiasshirleisouza.pdf. Acesso em 12 de maio de 2012.

Vilaça, M. L. C. (2008). Métodos de Ensino de Línguas Estrangeiras: fundamentos, críticas e ecletismo. In Revista Eletrônica do Instituto de Humanidades da UNIGRANRIO, Rio de Janeiro, 2008, pp. 73-85.

Ur, Penny. (2004). A course in language teaching: practice and theory. Cambridge University Press.

\section{AS AUTORAS:}

Adrina Silva é graduada em Letras (Português-Inglês) pela Universidade do Grande Rio (UNIGRANRIO).

E-mail: adrinacortes@ig.com.br

Luciana Valeiras Duque é graduada em Letras (Português-Inglês) pela Universidade do Grande Rio (UNIGRANRIO).

E-mail: luvaleiras@ig.com.br

Solimar Patriota Silva é mestra em Letras (Estudos da Linguagem) pela PUC-Rio e doutoranda em Linguística Aplicada pela Universidade Federal do Rio de Janeiro (UFRJ). 
Atualmente, é professora e coordenadora do curso de Letras da Universidade do Grande Rio (UNIGRANRIO).

E-mail: solimar.silva@unigranrio.com.br 